\title{
Design of The Learning Environment Considering the Gender Characteristics of Students
}

\author{
Maya Nickolaevna Shvetsova ${ }^{1 *}$, Lyudmila Aleksandrovna Dolinskaya ${ }^{1}$, Anastasiia \\ Vladimirovna Lukinova ${ }^{1}$, Marina Sergeevna Sotnikova ${ }^{1}$, and Anna Sergeevna Solntseva ${ }^{1}$ \\ ${ }^{1}$ Moscow Pedagogical State University (MPGU), Faculty of Pedagogy and Psychology, Department \\ of Educational Psychology, 119991, Moscow, Russia
}

\begin{abstract}
In this study, the motivation and cognitive characteristics of students in the implementation of a gender-based approach to teaching and their consideration in the educational process of boys and girls are presented. The purpose of the study is to verify empirically the effectiveness of the design of the learning environment considering the gender characteristics of students by analyzing the cognitive characteristics of children studying in different types of classes. In the study, the following methods were used: "Amthauer Intelligence Structure Test" adapted by L. A. Yasyukova, "Test for assessing the formation of reading skills", "Test for assessing the independence of thinking", test "Determining the level of school motivation and emotional attitude to learning (Spilberg-Andreeva)", as well as observation, comparison and assessment. It is shown that children studying in same-sex classes show a higher motivation for learning; their cognitive abilities manifest themselves differently than in mixed classes.
\end{abstract}

\section{Introduction}

Educational institutions always set the task of finding and introducing into the learning environment the most effective methods of teaching children for their comprehensive development, more efficient acquisition of knowledge and skills necessary for various spheres of life.

In this study, we consider the cognitive characteristics of children when implementing a gender-based approach to teaching, which implies separate teaching for boys and girls (classes are formed based on gender), while children study in the same school, that is, meet and communicate at breaks and extracurricular activities.

The gender aspects of childhood are of interest to specialists in various fields psychologists, neuropsychologists, educators and doctors. There is no need to dispute the difference between boys and girls: they differ from each other in the pace and quality of intellectual development, emotional reactivity, motivation, performance assessments and behavior. That is why in the learning process, it is especially important to consider all these aspects.

\footnotetext{
*Corresponding author: mn.shvetsova@mpgu.su
} 
E. M. Aleksandrovskaya [1], G. M. Breslav, B. I. Khasan [2], V. E. Kagan [3], T.P. Khrizman, V. D. Yeremeyeva [4] and others indicate the importance of selecting content, forms and teaching methods in accordance with the age and gender characteristics of students. The most important in this case is the initial stage of teaching. Not only school successes, but also the formation of the personality depend on how much the requirements made by the school will be adequate to the capabilities of boys and girls. Psychology and pedagogy operate with enough empirical data that emphasize the importance of the sexual factor in mental development. By the beginning of schooling, girls and boys are characterized by several semi-determined features of various origins, which must be considered in the educational process.

Based on the foregoing, the purpose of our study is to verify empirically the effectiveness of the design of the learning environment considering the gender characteristics of children by analyzing the cognitive characteristics of children studying in different types of classes.

\section{Methods}

The sample consisted of four mixed classes and four classes with separate education (two boys' classes and two girls' classes) and was equalized by the number of boys and girls. The study involved $2005^{\text {th }}$ grade students of the Moscow schools No. 1137 and No. 760 named after A.P. Maresyev.

The research methods were grouped as follows: the methods for identifying motivation for learning "Determining the level of school motivation and emotional attitude to learning (Spilberg-Andreeva)"; methods for determining the cognitive characteristics of children: "Amthauer Intelligence Structure Test", "Test for assessing the formation of reading skills", as well as "Test for assessing the independence of thinking", taken from the methodological complex Forecast and prevention of learning problems in grades 3-6 of L. A. Yasyukova [5]. All methods are adapted for the $5^{\text {th }}$ grade.

\section{Results}

The study of school motivation and emotional attitude to learning is presented in Table 1 .

Table 1. The results of the study according to the methodology "Determining the level of school motivation and emotional attitude to learning"

\begin{tabular}{|c|c|c|c|c|c|c|c|c|c|c|c|c|}
\hline & \multicolumn{4}{|c|}{ Boys' classes } & \multicolumn{3}{c|}{$\begin{array}{c}\text { Boys from mixed } \\
\text { classes }\end{array}$} & \multicolumn{3}{c|}{ Girls' classes } & \multicolumn{2}{c|}{$\begin{array}{c}\text { Girls from mixed } \\
\text { classes }\end{array}$} \\
\hline & high & average & low & high & average & low & high & average & low & high & average & low \\
\hline $\begin{array}{c}\text { Cognitive } \\
\text { activity (\%) }\end{array}$ & 73 & 23 & 4 & 25 & 60 & 15 & 60 & 33 & 15 & 53 & 35 & 12 \\
\hline $\begin{array}{c}\text { Anxiety } \\
(\%)\end{array}$ & 5 & 68 & 27 & 0 & 45 & 55 & 6 & 47 & 47 & 6 & 59 & 35 \\
\hline Anger (\%) & 23 & 54 & 23 & 15 & 50 & 35 & 13 & 40 & 47 & 6 & 53 & 41 \\
\hline
\end{tabular}

As one can see from the data presented in Table 1, in girls' classes, the level of cognitive activity is slightly higher than that of girls from mixed classes. However, there are no significant differences between these classes. In boys' classes, cognitive activity indicators are significantly higher than in boys studying with girls. The overwhelming majority of boys from mixed classes have an average level of cognitive activity.

Among girls from mixed classes, the average level of anxiety predominates, while among girls studying separately, average and low levels of anxiety are equally apparent. Anxiety 
among boys who study with girls is low, while among boys studying separately, the average level of anxiety is more pronounced.

Anger among girls from separate classes and mixed classes does not significantly differ, but we can see a tendency to increase it in classes where girls study without boys; a similar situation is with boys. Anger is lower in mixed classes.

The analysis of cognitive motivation by the same methodology showed that in mixed classes motivation is lower and there is a negative emotional attitude to learning, and in classes where only girls and only boys are taught, a higher level of cognitive motivation is revealed.

Next, we analyzed the results of the "Amthauer Intelligence Structure Test" and the "Test for assessing the independence of thinking" (from the methodological complex Forecast and prevention of learning problems in grades 3-6 by L. A. Yasyukova) [5]. Here we give only general conclusions.

Summing up the results of the $5^{\text {th }}$ graders, we can say that unlike children from separate classes boys and girls studying together have very few high indicators and more weak indicators.

In girls' classes, girls are better developed in abstract thinking, independent thinking, spatial thinking and random-access memory. However, girls studying with boys have better categorization. Indicators on such scales as intuitive and logical conceptual thinking, erudition and figurative synthesis are at about the same level.

In boys' classes, intuitive conceptual thinking, abstract thinking and independent thinking are better developed. Boys from mixed classes are developed in categorization and figurative synthesis. Almost at the same level are logical conceptual thinking, spatial thinking and random-access memory.

Among boys and girls studying together, the indicators on the categorization scale are higher than in children from classes with separate education. We think this is due to the fact that during classes, children hear the point of view not only of their gender, but also of the opposite, which leaves their mark on their thinking and allows them to look at the problem from the other side.

"Test for assessing the formation of reading skills" (cognitive GLA (General Learning Activities) (from the methodological complex Forecast and prevention of learning problems in grades 3-6 by L. A. Yasyukova ) showed that children from classes with a separate type of education have higher indicators. This suggests that among boys and girls who study separately, the formation of reading skills is at a higher level than in children from mixed classes. The main mistakes of the children were associated with fluent reading and as a consequence of this - inattention. Therefore, we can conclude that children from separate classes are more attentive.

\section{Discussion}

Gender equality and gender consideration in research are one of the six priorities of the European Research Area (ERA). The integration of the gender aspect in the content of research and teaching is one of its three goals, which is by far the least realized [6].

Modern studies of the gender approach to teaching show a difference in the motivation of girls and boys of different ages [7,8], for example, in teaching a foreign language. Male students are more likely to show low quality and externally controlled motives, while girls are more likely to show higher quality, as well as internally regulated motives [9], which is consistent with our study showing the need for gender-based teaching. Studies [10] of indicators of success and nonsuccess of mental efforts showed that, when dynamic tasks were presented, intrinsic motivation and frustration increased in female students, girls were more prone to research behavior, while boys showed more focused solutions. That is also 
consistent with our results, that cognitive abilities develop differently, and in separate classes, the propensity to manifest certain qualities of thinking varies.

Some studies show that gender does not have such a significant effect on school success and the development of cognitive abilities, as the article [11] summarizes 74 studies $(\mathrm{N}=$ 80,145), which simultaneously studied the predictive power of intelligence and motivation for school achievements. The authors claim that no significant values were found for class level, school uniform or gender. $66.6 \%$ were unambiguously explained by intelligence and $16.6 \%$ were explained by motivation, that is, intelligence and motivation make a significant and unique contribution to the prediction of school achievements. That is also shown in our study, with the only difference being that we tried to study the components of intelligence or cognitive abilities, showing that gender differences lie in the nuances and features of cognitive development and not in the assessment of intelligence in general.

It is often believed that the sex of a child, especially a girl, plays an important role in reducing educational opportunities [12]. Few researchers have tried to study this issue in detail. To this end, in the study [13], different approaches were used to evaluate gender stereotypes. Eighty-one university students ( 65 women, average age $=23.60$ years old) received a fictitious profile of an 8-year-old child with the task of teaching them on Skype. The profile of the child was experimentally processed considering gender (boy or girl) and gender stereotype. The results showed that participants rated girls as less capable of learning than boys in physics and provided less scientific information during teaching. Gender stereotypical girls were perceived as the least inclined to learning. These findings are important because they demonstrate clear educational deficiencies for girls due to their gender and the influence of stereotypes. Although this study was of interest to us, we want to note that it was not conducted in the Russian sample, where gender equality exists for a much longer period than in Europe and the USA. For this reason, perhaps this stereotyping does not apply to Russian attitude system. In any case, in our research, when communicating with teachers and observing, such accents were not noticed. We tend to emphasize gender characteristics that certainly exist.

Thus, we can state that studies of gender issues in education are conducted with different intensities; the problem of a gender approach to education differs in Russia [1-4] and abroad $[14,15]$. In the study of gender approaches in teaching, we focus more on the nuances that really accompany the development of girls and boys, rather than on issues of equality and stereotypes that accompany gender perception and that it is desirable to consider in education, so that it more and more meets the interests of the development of each child.

\section{Conclusion}

Based on the results of the study, we can identify emerging trends. The methodology "Determining the level of school motivation and the emotional attitude to learning" (Spilberg-Andreeva) showed that the level of cognitive activity in separate classes was higher than in mixed ones. The level of anxiety in boys from mixed classes was lower and in girls was higher. The level of anger (aggressiveness) in separate classes was lower for girls and higher for boys. Children studying separately were more positive about learning and their motivation was higher.

It should be noted that students from separate classes showed higher indicators by such methods as: "Amthauer Intelligence Structure Test" (adapted by L. A. Yasyukova ), "Test of the independence of thinking" and "Test for the assessing the formation of reading skills". They suggest that the intellectual abilities of such children are slightly higher.

Children from mixed classes more often asked what the task was and were less attentive. Girls and boys studying separately are more successful in learning activities than children studying together. Thus, we can argue that the separate teaching of boys and girls is more 
effective in terms of the development of their motivation for learning and cognitive abilities. Among the reasons, it can be assumed that in same-sex classes, teachers have an opportunity to take into account the characteristics of children and structure the lesson in accordance with the gender characteristics of the perception and processing of information. In addition, it is possible that in same-sex classes, competition in educational activities is higher, which especially affects boys. In Russian school, it is customary to form classes according to the age criterion, and boys lose to girls of their age in physiological development, and girls in mixed classes inevitably become intellectual leaders, which can negatively affect the development of boys. Design of the learning environment considering the gender principle, when children study separately, but at the same time meet at breaks, school events and extracurricular activities, can be considered promising.

\section{References}

1. E.M. Aleksandrovskaya, N.I. Kokurkina, N.V. Kurenkova, Psychological support for schoolchildren: a textbook for universities (Akademiya, Moscow, 2002)

2. B.I. Khasan, G.M. Breslav, Gender and education: Analysis of gender-identity conflict (KrGU, Krasnoyarsk, 1996)

3. D.N. Isayev, V.Ye. Kagan, Sexual education of children. Medical and psychological aspects (Meditsina, Leningrad, 1988)

4. V.D. Yeremeyeva, T.P. Khrizman, Boys and girls - two different worlds. Neuropsychology - for teachers, educators, parents, school psychologists (Linka-Press, Moscow, 1998)

5. L.A. Yasyukova, Forecast and prevention of learning problems in grades 3-6 (IMATON, Saint Petersburg, 2010)

6. R. Palmén, L. Arroyo, J. Müller, S. Reidl, M. Caprile, M. Unger, Eval. Program Plan. 79, (2020)

7. A. Widlund, H. Tuominen, A. Tapola, Learn. Instr. 66, (2020)

8. K.M.Y. Law, ShuangGeng, T. Li, Comp. Edu. 136, 1-12 (2019)

9. W.L. Quint Oga-Baldwin, L. K. Fryer, Heliyon 6(5), (2020)

10. S. Zander, M. Montag, S. Wetzel, S. Bertel, Computers \& Education 143, (2020)

11. K. Kriegbaum, N. Becker, B. Spinath, Edu. Res. Rev. 25, 120-148 (2018)

12. A. Mizala, F. Martínez, S. Martínez, Teaching Teacher Edu. 50, 70-78 (2015)

13. C. Newall, K. Gonsalkorale, E. Walker, G.A. Forbes, K. Highfield, Contemp. Edu. Psy. 55, 30-41 (2018)

14. Yu. Zen, T. Chiyonobu, M. Yuge, I. Yokota, M. Morimoto, S. Teramukai, H. Hosoi, Brain and Development 41(9), 760-768 (2019)

15. U. Tellhed, M. Bäckström, F. Björklund, J. Vocational Behavior 104, 1-13 (2018) 